\title{
FISIOLOGIA DE LAS HORMONAS SEXUALES EN LA INFANCIA
}

\author{
Dr. Alberto Duarte Contreras, M.D.*
}

\section{I - INTRODUCCION}

Aun cuando el sistema endocrino se desarrolla durante los primeros meses de la vida fetal, se acepta que los órganos genitales permanecen en reposo durante la infancia y que su actividad fisiológica sólo se inicia en los años que preceden de inmediato a la menarca. Concepción ésta que debemos recibir con reserva, puesto que no se han hecho investigaciones exhaustivas sobre eventuales funciones de los ovarios inmaduros; y sospechamos que en un futuro no lejano se nos pueda hablar de una posible contribución de las gónadas al equilibrio endocrino de la niña.

\section{II - INFLUenCIA DE LAS GONADAS SOBRE EL CRECIMIENTO Y DESARROLLO}

\section{A. - PERIODO PRENATAL}

Hay experiencias que parecen demostrar que la normogénesis sexual durante la vida embrionaria está regida por hormonas gonadales. Tanto las suprarrenales como las gónadas provienen embriológicamente del mismo germen primordial. Al experimentar en animales se ha constatado que embriones castrados de uno $u$ otro sexo desarrollan siempre un tracto genital femenino; mas si luego se les implantan testículos embrionarios, estos embriones feminizados toman nuevamente la morfología del tipo masculino (1).

Los ovarios se encuentran relativamente grandes en los últimos meses de la vida fetal y se pueden reconocer en ellos numerosos folículos primordiales; mas no producen estrógenos, Las altas dosis de gonadotropina coriónica que se producen en la primera mitad del embarazo, no ejercen efecto alguno sobre las gónadas fetales. $Y$ en autopsias se ha podido demostrar que solamente en caso de determinadas enfermedades como toxemia o diabetes, es posible una estimulación patológica sobre los ovarios fetales (2).

Durante este período las suprarrenales tienen capacidad funcional $y$ pueden participar en la esteroidogénesis. La corteza se aprecia notoriamente grande y la zona reticular esencialmente ancha. $Y$ los exámenes bioquímicos de extractos corticales de fetos de 7 o más meses han démostrado una cantidad relativamente abundante de esteroides, los que sin duda alguna juegan un papel importante en el metabolismo fetal $(2,3)$.

La hipófisis tiene también mucho que ver en el desarrollo de las góna-

* Médico Jefe del Departamento de GinecoObstetricia del Hospital San Juan de Dios. Cúcuta, Colombia. 
das embrionarias: y así, al hipofisectomizar embriones de conejos machos durante el período de desarrollo de sus genitales externos se obtienen animales seudohermafroditas, trastorno que se corrige al administrar hormona gonadotropa a estos embriones hipofisectomizados (1).

Se han demostrado granulaciones específicas en el lóbulo anterior de la hipófisis, lo mimso que secreción de hormona tireotropa y corticotropa durante los tres últimos meses de la vida fetal. $Y$ es probable que todas las glándulas endocrinas funcionen durante la vida intrauterina $(4,5)$.

\section{B - PERIODO DE LA INFANCIA}

Durante este período toda la actividad endocrina está orientada hacia el crecimiento somático y específicamente hacia el crecimiento lineal; y en ello juegan papel primordial la hormona del crecimiento y el tiroides (6).

Wilkins dice que el crecimiento somático en la primera infancia obedece primordialmente a una tendencia intrinseca del crecimiento, poseída por todos los tejidos más que a un factor específico de la hormona de crecimiento; y el hecho de que los enanos tengan un crecimiento normal durante los primeros años de vida, inclina a aceptar esta hipótesis (7).

Ignoramos, a la luz de los conocimientos actuales si la FSH y los estrógenos tengan también algo que ver con el aumento de talla y peso.

El sistema diencéfalo hipofisario ejerce una leve influencia sobre las gónadas, y gracias al método radio inmunológico se han podido demostrar débiles cantidades de hormonas gonadotropa y córticotropa de la hipófisis anterior.
$Y$ así sabemos con toda precisión que la hipófisis durante la edad infantil secreta la hormona folículo estimulante FSH y la luteinizante $L H$, secreción que es similar en niños de ambos sexos en función de la edad pero con retraso de un año en los varones comparándola con la observada en las niñas.

La FSH aumenta durante los cuatro primeros años (dos primeras etapas según el método de Tanner), y luego se estabiliza su producción. La LH por el contrario aumenta de manera regular durante toda la infancia (8).

La corteza suprarrenal produce cantidades apreciables de todos los metabolitos esteroideos normales, a excepción de los andrógenos cuya presencia es mínima; pero entre los 6 y los 10 años, en un momento dado en la secuencia del crecimiento y del desarrollo, las suprarrenales tienen un rápido aumento de su tasa ponderal y paralelamente sube la secreción de andrógenos $(2,3,4,5)$.

De los 3 a los 8 años el niño y la niña secretan tanto estrógenos como andrógenos en cantidades débiles pero constantes. $Y$ esta mínima producción de estrógenos explica el por qué una niña no se diferencia en sus hábitos de otra de similar edad portadora de disgenesia gonadal. $Y$ parecería lógico pensar que las mínimas cantidades de estrógenos detectables en las niñas fuesen producidas por los ovarios: pero encontrándose una tasa relativamente igual en los dos sexos, debemos aceptar que su origen es suprarrenal y prueba de ello el hecho de que el peso de las suprarrenales es proporcional a la cantidad de estrógenos eliminados. Pero la observación de que el útero de mujeres o de animales castrados a temprana edad sea más pequeño 
que el de los no castrados nos hace ver que algunos estrógenos pueden ser secretados por los ovarios antes de la menarca $(1,4)$.

\section{C - PERIODO PREMENARQUICO}

A partir de los $8 \circ 9$ años empieza la hipófisis a producir dosis crecientes de hormonas tropas. Poco se sabe sobre este "mecanismo disparador" de la hipófisis: estímulos hipotalámicos, herencia, madurez de los tejidos; $y$ en todos estos factores juegan papel preponderante las hormonas tiroideas y del crecimiento, el estado nutricional y aún las enfermedades (7).

Las hormonas tropas actuarán principalmente sobre el tiroides, las suprarrenales y las gónadas aumentando su actividad y haciendo que se efectúen todos aquellos cambios que intervienen en el desarrollo normal de la niña, con la aparición de caracteres sexuales secundarios, la menarca y la maduración de la mujer.

La FSH aumenta rápidamente entre los 9 y los 11 años hasta alcanzar en esta edad valores semejantes a los de la mujer adulta y se hace entonces responsable del comienzo y del mantenimiento de la función ovárica. La LH que venía en producción constante durante la infancia presenta una rápida elevación en el período premenárquico, sin alterar las tasas de FSH $(9,10)$.

Los ovarios aumentan por entonces de tamaño y sube la producción de foliculina pero sin que se presente ovulación ni producción de progesterona: es el momento conocido como "función vegetativa de las gónadas"; y con su aparición termina la infancia (2).

El eutioriodismo es indispensable para la correcta función gonadal, y prueba de ello es que el desarrollo y la aparición de los caracteres sexuales secundarios se retardan en las niñas con grave deficiencia tiroidea hasta cuando se les administre la hormona correspondiente (6).

Los andrógenos que se encuentran en la orina de las niñas son de procedencia suprarrenal; no se ha podido constatar en condiciones normales que provengan del ovario a excepción de aquellos casos en los cuales se encuentra o hiperplasia de las células hiliares o tumores masculinizantes del parénquima ovárico (11).

Los andrógenos además de su efecto anabólico y de su acción estimulante del crecimiento lineal y de la masa muscular son responsables de la aparición de la pilosidad pubiana $y$ auxiliar, del desarrollo de los grandes y de los pequeños labios, de la erectinilidad del clítoris y de las aréolas mamarias, del aumento de secreción de las glándulas sebáceas, de la aparición de una eventual acné y de un discreto cambio de voz hacia el tono grave.

Los estrógenos al igual que los andrógenos inician su ascenso de producción a partir de los 809 años y aumentan paralelamente en ambos sexos. A partir de los 9 años su producción se hace más acelerada, siendo mayor y más rápida su secreción en las niñas a punto tal que hacia la proximidad de la menarca la estimulación progresiva estrogénica sobre los diferentes tejidos estimula la diferenciación sexual y la aparición de los caracteres sexuales secundarios.

En las niñas de menarca tardía el aumento progresivo estrógeno andrógeno es mucho más lento y por lo tanto de mayor duración que el encontrado en aquellas que tienen una menarca temprana. 
Los estrógenos no actúan sobre el crecimiento somático. Activan la fusión de los cartílagos de conjugación al final del período de crecimiento actuando bien sea de manera directa sobre las células o inhibiendo el efecto de la hormona hipofisaria del crecimiento. Favorecen también el almacenamiento de las grasas. El crecimiento acelerado de una niña con precocidad sexual no es necesariamente el resultado de la síntesis elevada de los estrógenos, sino que, según Wilkins, representa más bien la actividad de la fuerza de crecimiento que es responsable del complejo proceso de la maduración sexual y del crecimiento somático (7).

Tanto la secreción de las hormonas sexuales como la aparición de la menarca guardan relación con la edad cronológica más que con el crecimiento somático. Pero este crecimiento somático no está necesariamente en relación ni con un peso ni con una talla dada, y es así como podemos observar niñas de talla baja que maduran a una edad más precoz que otras niñas de talla alta. Hay una relación muy estrecha entre peso, edad y maduración del esqueleto. El grado de maduración del esqueleto es el mejor indicador del estado de desarrollo; y así cuando se presenta la menarca cualquiera que sea la edad cronológica, la tasa de maduración esquelética se situará entre los $3 \frac{1}{2}$ y los 14 años. Entre los 7 u 8 años se inicia la diferenciación somática entre el niño y la niña. Uno o dos años más tarde la niña inicia un crecimiento más acelerado, y la menarca ordinariamente se presenta un año después de aparecer la tasa máxima de crecimiento. Se desconoce el mecanismo que rige el crecimiento rápido premenárquico, aun cuando parece depender de factores genéticos ya que los ge- melos tienen con frecuencia el mismo esquema de maduración $(7,11$, $13)$.

En esta etapa las gonadotropinas exógenas aumentan la secreción de estrógenos: de ello se deduce que la baja concentración de gonadotropinas puede ser un factor limitante en la iniciación de la menarca (8).

Durante la infancia el Clomifeno no induce la más mínima liberación de FSH ni de LH; mas no así durante la pubertad donde provoca una liberación intensa tanto de FSH como de LH, según los estudios de Franchimont y colaboradores (8).

\section{III - BIBLIOGRAFIA}

1 OKAER, R. et HECHTERMANS, R. "Physiologie de l'appareil génital de la naissance á la puberté". En: L'appareil génital féminin avant la puberté. Physiologie et Pathologie. Masson et Cie. Ed. Paris. Pág. 1, 1971.

2 UFER, J. Fisiología de las hormonas sexuales en las diversas etapas de la vida. En "Hormonoterapia en gíneco obstetricia". 2a. Ed. Alhambra, S. A. Madrid, Pág. 29, 1965.

3 WELLENBACH, B. Childhood Gynecologic Endocrinology. Ann. N. Y. Acad. Sci. 142 : 592, 1967.

4 HUFFMAN, J. The Gynecology of Childhood and Adolescence. W. B. Saunders Co. Philadelphia, 1968.

5 HUBBLE, D. Pediatrics Endocrinology. Blackwell Scientific Publications. Oxford, 1969.

6 DEWHURST, G. J. Las Hormonas sexuales. En Ginecología Pediátrica. Ed. Alhambra, S. A. Madrid, Pág. 2, 1964.

7 WILKINS, L. El desarrollo sexual del adolescente $y$ sus variaciones. En "Diagnóstico y tratamiento de las enfermedades endocrinas en la infancia y adolescencia". Ed. Espaxs, Barcelona. Pág. 203, 1966.

8 FRANCHIMONT, P., LEGROS, J. J., DECONINCK, B. et VALCKE, J. C. Les gonadotrophines pendant l'enfance et la puberté. En L'appareil génital féminin avant la puber- 
té. Phisiologie et Pathologie. XXVes Assises Francaises de Gynécologie. Masson et Cie., Ed. Pág. 34, 1971.

9 SIZONENKO, P. C. "Evolution des concentrations sanguines des hormones lutéinisante $(\mathrm{LH})$ et folliculo-stimulante (FSH) chez la fille de la naissance á la puberté". En L'appareil génital féminin avant la puberté. Physiologie et Pathologie. Masson et Cie. Ed. Paris. Pág. 45, 1971.

10 KULIN, H. E., ODELL, W. D., RIFKIND, A. B. and ROSS, G. T. Total gonadotropin ac- tivity in the urine of prepuberal children. J. Clin. Endocr. 27: 1123, 1967.

11 GOLDFARB, A. F. Pubertad. Clínicas Obst. Gin. 769, 1968.

12 WILLIAMS, R. H. The influence of the endocrine glands upon growth and development. En "Texbook of Endocrinology". Ed. W. B. Saunders Co. Philadelphia, Pág. 1017, 1968.

13 HARRIS' H. J. Problemas de crecimiento en el adolescente. Clínicas Méd. de Norte Am. $357,1965$. 